place and the uterus and bladder remained between the thighs for a week before advice was sought. They were then replaced and kept in fair position by a mechanical support. Comparative comfort was thus attained, but the strain of walking with crippled joints somewhat interfered with the usual result.

On May 29th, 1898, quinine solution was injected into the broad ligament on either side of the uterus. The full dose was not received as the syringe leaked. The after-rest was imperfect owing to a disturbance of the household by an epidemic of measles among the grand-children. Yet at the end of two months the patient got up with a perfectly fixed uterus. For many months she walked in her struggling way without the least discomfort from prolapse and then cystocele occurred. About Christmas-time the uterus prolapsed slightly and on Jan. 15th, 1899, a supplementary injection of quinine was given in the broad ligament. Since that date the comfort has been perfect. The patient wears a watchspring rabber ring to support the cystocele, but the uterus remains firmly fixed with its axis in that of the inlet of the pelvis. The perineal structures are absolutely lax but the uterus hangs upon its new supporting bosses which can be readily felt high up in the pelvis. As the patient walks she puffs and groans till her face becomes cyanotic, but even this strain does not displace the uterus. The patient was last seen on June 8th, 1899.

Considering that the patient is badly fed, that she has little comfort in her home, and that she earns her scanty subsistence by attending to, and often lifting, her three grand-children the result is eminently satisfactory

Guernsey.

\section{MULTIPLE NEURITIS THROUGH NECROSIS OF THE LOWER JAW CAUSED BY AN ILL-FITTING DENTURE ; EASY REMOVAL OF SEQUES-} TRUM ; RAPID RECOVERY.

By Montague D. Makuna, M.R.C.S. Eng., L R C.P.Lond.

THE patient, a female, aged 25 years, had suffered from facial neuralgia on and off for years past. In 1894 several decayed teeth were removed and she wore a denture which was ill-fitting. Subsequently a few more teeth decayed which were extracted and she wore another denture equally bad. She could not be persuaded to leave off wearing the denture and thus made herself a martyr to pain, resulting in insomnia, mental irritability, anorexia, and loss of body-weight from 11 st. in 1894 to $6 \frac{1}{7}$ st. in October, 1898. She consulted me on Oct. 10th last for motor paralysis, hyperæsthesia, wasting of the left upper limb, and swelling of the right side of the lower jaw from the external oblique ridge to the sym. physis. She bad four fairly good lower incisors, but the two canines were much decayed by the clasps of the denture and there were four decayed molars in the upper jaw. She was compelled to give up the denture. From Oct. 12th to Nov. 5th she received fifteen sittings of combined electric current. She was put on liquid diet with digestives, and bromoglobulin, cod-liver oil and hypophosphite emulsion, and phosphide of zinc were administered in succession. She also received anodynes and hypnotics. The tenderness of the upper limb gradually disappeared, and by the middle of November she regained motion and the muscular structure showed signs of filling in. She was also relieved of neurotic symptoms trom other parts of the body. Simultaneously with this constitutional treatment an incision was made along the right alveolar border of the lower jaw, reaching to the osseous surface, eucaine being used as an anæsthetic, and some purulent discharge was evacuated. The cavity was daily syringed with carbolic acid lotion and an antiseptic mouth wash was used. Notwithstanding the swelling rapidly increased and caused intense pain. Four leeches were applied externally, giving temporary relief, followed by puralent discharge through one of the leech bites. Shortly afterwards the sequestrum could be felt by a probe loose in its cavity. On Dec. 1st three grains of eucaine in solution were injected along the alveolus and the discharging cavity was enlarged. The sequestrum was drawn up by the forceps and was removed from the cavity by the patient with her fingers. Still the necrosis kept on creeping towards the symphysis. Profiting by the experience of Sir J. Tomes ${ }^{1}$ I adopted "a less conservative line of treatment" and removed all the teeth, with the result that the purulent discharge ceased and the pain and swelling subsided. The so-called hysterical symptoms disappeared and appetite and sleep were restored. After a gradual decline in bealth and weight for five years the patient regained her weight in three months, weighing 11 st. in April last. It is needless to state that during her prolonged illness she had been treated for many ills that flesh is heir to and had swallowed as many patent nostrums as she could get. The case is remarkable for the long-suffering of the patient, the easy removal of the sequestrum, and the rapid recovery.

Treherbert.

\section{"ON THE EFFECTS OF PRIMULA OBCONICA ON} THE SKIN."

\section{BY F. A. BARTON, L.R.C.P. LOND., M.R.C.S. ENG.}

I OBSERVE that the subject of the irritation caused by handling the primula obconica is again drawing some attention and I venture to think that a case of this nature which came under my care a year or so ago may be of interest.

A gardener came to see me complaining of irritation and swelling of his eyelids which were so great that he could hardly see. His penis, he said, was painful and swollen and there was a troublesome rash on his hands. Three months previously he had had a similar attack, though not so severe, and on questioning him closely be admitted that at that time he had much to do with primulæ, of which he had a large number in pots. Nearly a week before the present attack came on the patient had mored all the primulæ from one hot house to another, and among them were many specimens of primula obconica. In the present attack the eyelids and penis swelled before the eraption on the hands appeared, though this followed a few hours afterwards. The irritation and itching were almost intolerable. He bad a habit of rubbing his eyes when at work. On examination. the lids were very cedematous, especially the lower ones, and were shining and tense. The penis was enormously swollen with odema, especially round the $f_{1} \rightsquigarrow n u m$ and foreskin. The hands showed an interesting condition. They were hard and borny from manual work but the forefingers and thumbs more especially on the dorsal aspect were cedematous, red, and violently inflamed, the eruption extending over the radial half of the back of the hand 'and fading away toward the base of the little finger. "The eruption consisted of discrete papules and small vesicles scattered pretty thickly on a very inflamed red area which covered nearly all the dorsum of the hand, fading at its edge into healthy skin at the wrist and ulnar edge of the hand. On the eyelids and penis the papules were much fewer and more scattered. The patient was not much surprised when I told him the cause of his trouble as he was aware that some of the primulæ were "poisonous."

In ten days he was practically well and in the meantime he brought me some leaves and flowers to examine. I removed some of the hairs from the leaves and examined them microscopically in glycerine. I found that most of them ended in a fine horny point between which and the main trunk of the hair were some transverse markings or, as I imagined, planes of fission, and I think it not unlikely that the eruption is caused by the penetration of this fine point into the skin where fracture takes place, the point being left in the dermis. This would account for some of the irritation, but it is open to quastion whether the inflammation is more violent than could be accounted for by simple irritation from this cause. It is conceivable that, as in the jequirity seeds, there may be some irritative ferment contained in the hair ends. Another curious fact and, I think, one worth notice is that occasionally there is a long period between the con. tact of the leaves and the eruption. Dr. Kirk on one occasion when experimenting in corpore vili passed ten days before the rash appeared, and in the abcve case there was, so to speak, an incubation of a week.

Cheniston-gardens, $\mathrm{W}$. 


\section{d attirur}

or

\section{HOSPITAL PRACTICE, BRITISH AND FOREIGN.}

Nulla autem est alia pro certo noscendi via, nisi quamplurimas et morborum et dissectionum historias, tum aliorum tum proprias eollectas habere, et inter se comparare.-MoRGsGNI De Sed. et Caus. Morb., lib. iv. Procmium.

\section{WESTMINSTER HOSPITAL.}

TWO CASES OF ERYSIPELAS TREATED WITH ANTI-STREPTOCOCCIC SERUM.

(Under the care of Dr. W. MurRelL.)

IN many suppurative conditions the anti-streptococcic serum is of value. The serum is chiefly deserving of injection in cases in which septic absorption has occurred, and in which the presence of the streptococcus has been demonstrated. At various times much doubt has been felt as to the connexion of erysipelas with the ordinary streptococcus, but the fact that the anti-streptococcic serum has proved useful in cases of erysipelas is a powerful argument in favour of erysipelas being due to the ordinary streptococcus. The anti-streptococcic serum is hardly advisable in every case of erysipelas, for the majority of cases have only a short course and early and complete recovery is almost invariable. The serum is likely to prove of most benefit in severe cases of erysipelas of the face, in which the prognosis is far graver than in ordinary cases. The success of the treatment in Case 1 is especially striking. For the notes of the cases we are indebted to Mr. Frank F. Bond, house physician.

CASE 1.-A woman, aged 27 years, was admitted into Westminster Hospital at 4 P.M. on May 19th, 1899. The patient had first noticed a tender swelling on the mucous membrane of the right nostril on the 17th. A few hours afterwards the outer surface of the nostril was red and swollen and by the next morning the rash had extended to both cheeks. There was no history of an abrasion on the skin or mucous membrane. On admission a red brawny swelling was found involving the whole face and extending upwards over the forehead as far as the roots of the hair. Both ears were affected and the rash extended downwards into the neck as far as the level of the hyoid bone. The eyelids were considerably swollen and partially closed. The patient was quite unconscious. The temperature on admission was $103^{\circ} \mathrm{F}$. Immediately after admission 10 cubic centimetres of anti-streptococcic serum were injected into the subcutaneous tissue of the abdominal wall. The face was dusted with a powder consisting of one part of zinc oxide to two parts of powdered starch and was protected from the air by a lint mask. Half an ounce of brandy was administered every three hours. During the uight the temperature ranged between $101^{\circ}$ and $103^{\circ}$. The patient was delirious and did not completely regain consciousness until 5 o'clock on the following morning. A $8 \mathrm{~A} . \mathrm{M}$. on the 20 th the temperature had fallen to $101^{\circ}$, but during the day it rose again, and at 4 P.M. it stood at $104.4^{\circ}$. At 9.30 P.Mr. a second injection of anti-streptococcic serum (10 cubic centimetres) was administered. The face was still considerably swollen and the eyes were almost closed. The eyelids were bathed with a weak solution of boric acid. On the 21st the temperature fell to $99.8^{\circ}$ and did not at any time subsequently reach $100^{\circ}$. The face was not so much swollen and the eyes were fully open. Two more injections of anti-streptococcic serum were administered, one on the 21 st and one on the $22 \mathrm{nd}$. The temperature fell to normal on the morning of the 22 nd and remained at that point. On the 24th the rash had almost entirely disappeared and the face was desquamating in large flakes. The patient was well enough to get up on the 25 th.

CASE 2.-A girl, aged 16 years, was admitted into Westminster Hospital at 5 P.M. on May 20th, 1899. The patient had first noticed a red tender spot immediately below the right ala nasi on the morning of the 20th. She stated that she had observed no abrasion there previously. The swelling rapidly spread to both sides of the face. On admission there was a red brawny swelling involving the nose, the upper lip, and both cheeks extending on both sides as far as the prominence of the malar bones. The margins were well defined. The nose and the upper lip were much swollen and there were a few small vesicles on the alæ of the nose. The temperature was $100^{\circ} \mathrm{F}$. The patient was treated in precisely the same way as was the patient in Case 1. The first injection of anti-streptococcic serum was administered at 9.30 P.M., the temperature then standing at $102.2^{\circ}$. On the morning of the 21st the temperature had fallen to $98^{\circ}$. At noon a second injection of 10 cubic centimetres of the serum was given. The temperature at midnight rose to $99.2^{\circ}$, but fell next morning to normal and did not subsequently rise above $99^{\circ}$. A third injection was administered on the 22 nd. On the 24th the nose was still a little swollen, but otherwise the rash had practically disappeared. Slight desquamation was taking place along the edges of the alæ nasi ; the rest of the skin was normal. She was able to leave her bed on the 25 th.

Remarks by Mr. BoND.-Considerable attention having recently been devoted to the treatment of various forms of streptococcus infection by the injection of anti-streptococcic serum I have thought that the above cases may be of interest as evidence of the value of this method of treatment in facial erysipelas. The serum is extensively used in the wards of Westminster Hospital and the most successful results have been obtained in case $\mathrm{S}$ of erysipelas. On referring to the above cases the following points are noticeable. 1. The rapidity with which an improvement in the patient's general condition is obtained. In Case 1, although the patient was suffering severely from septic poisoning, as evidenced by pyrexia and delirium, within a few hours the temperature was reduced and she was perfectly rational and in three days the temperature had fallen to normal. 2. The fact that the disease may be checked in the early stages by the use of the anti-streptococcic serum. Case 2 came under treatment within 12 hours of the commencement of the illness. There was a marked improvement a few hours after the first injection of the serum and within 36 hours the temperature fell to normal. 3. No local symptoms were caused by the injection except a slight tenderness at the point of inoculation which passed off without treatment in the course of a few hours. The injections were administered alternately on the two sides of the abdomen below the umbilicus, this being a site which is but little exposed to pressure. I am indebted to Dr. Murrell for permission to publish the cases.

\section{BIRMINGHAM GENERAL HOSPITAL.}

A CASE OF HYDATID CYST OF THE LUNG TREATED BY INCISION AND DRAINAGE; RECOVERY.

(Under the care of Dr. R. M. SIMON and Mr. LEONARD GAMGEE.)

IN the Mirror of Hospital Practice on Oct. 15th, 1898, we published the notes of a case of hydatid of the lung in many ways very similar to the following case. The surgical treatment by incision has a very high rate of success, for according to Tuffer's statistics more than 90 per cent of the cases (55 out of 61 ) recover.: Aspiration has frequently proved fatal and is now practically inadmissible. Bond's method of treating hydatids by incision and removal of the cyst without subsequent drainage is not so well suited for the lung as for intra-abdominal hydatid tumours.

A young woman, aged 21 years, was admitted into the Birmingham General Hospital on Nor. 4th, 1898, under the care of Dr. R. M. Simon. The patient complained of cough, shortness of breath, and pain in the right side of the chest. She gave the following history. In February, 1897, while out walking on a very cold morning, she was suddenly seized with acute pain in the right side of the chest over the region of the breast. The pain became less severe, but did not completely disappear for a period of nine weeks. After this the pain recurred, though not severely, every few weeks. In February, 1898, she had another attack of pain in the same region lasting for 12 weeks. From this time the patient remained apparently quite well until a week before her admission into the hospital. The present attack began with pain in the right side of the chest, shivering, and sweating. 